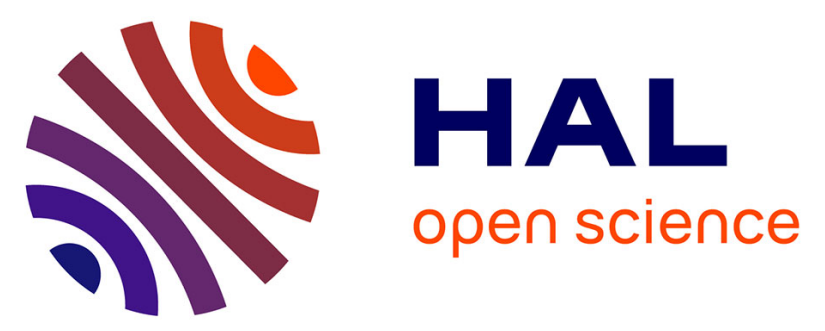

\title{
Panel gene profiling of small bowel adenocarcinoma, results from the NADEGE prospective cohort
}

Thomas Aparicio, Magali Svrcek, Julie Henriques, Pauline Afchain, Astrid Lièvre, David Tougeron, Johan Gagniere, Eric Terrebonne, Guillaume Piessen, Jean-Louis Legoux, et al.

\section{To cite this version:}

Thomas Aparicio, Magali Svrcek, Julie Henriques, Pauline Afchain, Astrid Lièvre, et al.. Panel gene profiling of small bowel adenocarcinoma, results from the NADEGE prospective cohort. International Journal of Cancer, 2021, 148 (7), pp.1731-1742. 10.1002/ijc.33392 . hal-03038573

\section{HAL Id: hal-03038573 https://hal.science/hal-03038573}

Submitted on 15 Dec 2020

HAL is a multi-disciplinary open access archive for the deposit and dissemination of scientific research documents, whether they are published or not. The documents may come from teaching and research institutions in France or abroad, or from public or private research centers.
L'archive ouverte pluridisciplinaire HAL, est destinée au dépôt et à la diffusion de documents scientifiques de niveau recherche, publiés ou non, émanant des établissements d'enseignement et de recherche français ou étrangers, des laboratoires publics ou privés.

\section{(c)(1)}

Distributed under a Creative Commons Attribution| 4.0 International License 


\section{Panel gene profiling of small bowel adenocarcinoma, results from the NADEGE prospective cohort}

Running title: Genomic profiling of small bowel adenocarcinoma

Thomas Aparicio (1), Magali Svrcek (2), Julie Henriques (3, 4), Pauline Afchain (5), Astrid Lièvre (6), David Tougeron (7), Johan Gagniere (8), Eric Terrebonne (9) Guillaume Piessen (10), JeanLouis Legoux (11), Cédric Lecaille (12), Marc Pocard (13), Jean-Marc Gornet (1), Aziz Zaanan (14), Sandrine Lavau-Denes (15), Thierry Lecomte (16), David Deutsch (17), Dewi Vernerey (3, 4), Pierre Laurent Puig $(18,19)$.

(1) Department of Gastroenterology and Digestive Oncology, Saint Louis Hospital, APHP, Université de Paris, Paris, France

(2) Sorbonne Université, Department of Pathology, Saint Antoine Hospital, APHP, Paris, France

(3) Methodology and Quality of Life Unit in Oncology, EA 3181, University Hospital, Besançon, France

(4) Bourgogne Franche-Comté University, INSERM, Etablissement Français du Sang Bourgogne Franche-Comté, UMR1098, Interactions Hôte-Greffon-Tumeur/Ingénierie Cellulaire et Génique, Besançon, France

(5) Department of Oncology, Saint Antoine Hospital, APHP, Paris, France

(6) Department of Gastroenterology, Pontchaillou Hospital, Rennes 1 University; INSERM U1242, Rennes, France

(7) Department of Hepato-Gastroenterology, CHU de Poitiers, France

(8) Department of Digestive and Hepatobiliary Surgery, University Hospital of ClermontFerrand, U1071 INSERM, Clermont-Auvergne University, Clermont-Ferrand, France

(9) Department of Gastroenterology, CHU Haut-Lévêque, Pessac, France

(10) Department of Digestive and Oncological Surgery, Claude Huriez University Hospital, University Lille, Lille, France

(11) Department of Hepato-Gastroenterology and Digestive Oncology, CHR La Source, Orléans, France

(12) Department of Gastroenterology, Polyclinic Bordeaux Nord, Bordeaux, France 
(13) Department of Digestive Surgery, Lariboisière Hospital, APHP, Paris, France

(14) Department of Gastroenterology and Digestive Oncology, Georges Pompidou Hospital, APHP, Université de Paris, Paris, France

(15) Department of Oncology, CHU Dupuytren, Limoges, France

(16) Department of Hepato-Gastroenterology and Digestive Oncology, Trousseau Hospital, CHU Tours, Tours, France

(17) Department of Gastroenterology, Avicenne Hospital, APHP, Bobigny, France

(18) Centre de Recherche des Cordeliers, Sorbonne Université, Inserm, Université de Paris, Paris, France

(19) Department of Biology, Georges Pompidou Hospital, APHP, Université de Paris, Paris, France.

Correspondence: Prof Thomas Aparicio

Gastroenterology and Digestive Oncology, Saint Louis Hospital, Université de Paris, 1 avenue Claude Vellefaux, 75010, Paris, France

E-mail: thomas.aparicio@aphp.fr, Tel: +33 1424995 97, Fax: +33 142499168

Key words: small intestine adenocarcinoma, genomic profiling, cohort study, Crohn's disease, Lynch syndrome, MMR status.

\section{Novelty and impact:}

- A genomic alteration is observed in $90.3 \%$ of the small bowel adenocarcinoma.

- The most frequent gene alterations are in KRAS, TP53, PIK3CA, APC, SMAD4 and ERBB2.

- Tumours associated with Crohn disease and Lynch syndrome have specific alterations.

- Genomic alteration had no prognostic effect except dMMR status.

\section{List of abbreviations}


AGEO: Association des Gastro-Entérologues-Oncologues

AJCC: American Joint Committee on Cancer

BIONADEGE: analyse BIOlogique de la cohorte Nationale d'ADEnocarcinome de l'intestin GrèlE

CT: Computed tomography

Cl: confidence interval

dMMR: deficient mismatch repair

DNA: desoxyribonucleic acid

GERCOR: Groupe Coopérateur Multidisciplinaire en Oncologie

HR : hazard ratio

IHC: immunohistochemical

MSI: microsatellite instability

MMR: mismatch repair

NADEGE: cohorte Nationale d'ADEnocarcinome de l'intestin GrêlE

NGS: Next generation sequencing

OS: Overall survival

pMMR: proficient mismatch repair

SBA: Small bowel adenocarcinoma

TMA: Tissue microarrays

UICC: Union for International Cancer Control. 


\section{Abstract}

Small bowel adenocarcinoma (SBA) is a rare tumour. Large genomic analyses with prognostic assessments are lacking. The NADEGE cohort has enrolled 347 patients with all stage SBA from 2009 to 2012. Next generation sequencing investigates the presence of 740 hotspot somatic mutations in a panel of 46 genes involved in carcinogenesis. The mismatch repair (MMR) status was assessed by immunochemistry. We have collected 196 tumour samples and 125 had conclusive results for mutation analysis. The number of mutations was 0 in $9.6 \%$ of tumours, only 1 in $32.0 \%, 2$ in $26.4 \%$ and $\geq 3$ in $32.0 \%$. Altogether, at least one genomic alteration was observed in $90.4 \%$ of tumour. The most frequent genomic alteration was in KRAS (44.0\%), TP53 (38.4\%), PIK3CA (20.0\%), APC (18.4\%), SMAD4 (14.4\%) and ERBB2 (7.2\%) genes. KRAS mutations were more frequent in synchronous metastatic tumours than in localized tumours $(72.7 \%$ vs $38.2 \%, \mathrm{p}=0.003)$. There was no significant difference in the mutation rates according to primary location for the most frequently altered gene. ATM, FGFR3 and FGFR1 gene alterations were associated with Lynch syndrome and IDH1 mutations with Crohn disease. dMMR tumours were associated with younger age, localized tumours, less KRAS but more SMARCB1 mutations. No genomic alteration was associated with overall survival. There is a trend for better survival in patient with dMMR tumours. In conclusion, there is a different genomic alteration profile in SBA according to predisposing diseases. No association between genomic alterations and prognoses was observed except for a trend of better prognoses associated with dMMR. 


\section{BACKGROUND}

Small bowel adenocarcinoma (SBA) is a rare tumour of poor prognosis (1). Nevertheless, it is the first aetiology of small bowel cancer in France (2) and second aetiology in the USA (3). Concordant findings report an increasing incidence of SBA $(2,4,5)$.

Few studies have investigated the molecular phenotype of SBA. A previous study reports that the genomic profile of SBA is closer to colon adenocarcinoma rather than gastric adenocarcinoma (6). Recently, a large genomic analysis mainly on stage IV tumours has reported a distinct profile of SBA compared to gastric or colon adenocarcinoma (7). Indeed, if RAS mutation prevalence is similar to colon cancer, APC mutations are much less frequent, $B R A F$ rarely involved $\mathrm{V} 600 \mathrm{E}$ point mutations and ERBB2 mutations or microsatellite instabilities (MSI) are more frequent than in colon cancer (7-10). A prognostic value had been inconsistently associated with ERBB2 mutations (11), MSI (9) or TP53 mutations (12). Some differences of genetic profile were reported according to the small bowel segment. Indeed, several studies found that ERBB2 mutations were more frequent in duodenum $(7,8,10)$, but conflicting results are reported for other genetic alterations according to localisation across the studies. The limits of most studies are the small number of patients and the lack of clinical data or prognosis evaluation.

The NADEGE cohort has enrolled prospectively consecutive patients with all stages of SBA during a four-year period in France. Clinical tumour characteristics differ according to sporadic SBA or secondary to a predisposing disease. Crohn disease was significantly associated with younger age, poor differentiation, and ileum location, whereas Lynch syndrome was associated with younger age, poor differentiation, an early stage, and duodenum location. Tumour grade and stage were the main prognostic factors (13). The BIONADEGE study is an 
ancillary study of the NADEGE cohort aimed to assess the genomic profile according to a predisposing disease for SBA, to SBA localisation or stage and assess the prognostic value of these genomic alterations.

\section{PATIENTS AND METHODS}

\section{Study population}

The NADEGE cohort has recruited 347 patients in 74 participating French institutions from January 2009 to December 2012. All consecutive stage I-IV patients with histologically proven, newly diagnosed or with recurrent SBA (local or distant) were enrolled into the NADEGE cohort. Ampullary and non-adenocarcinoma tumours were excluded. TNM staging was done according to the criteria of AJCC and UICC (7th UICC TNM Staging System) performed at diagnosis by computed tomography (CT) scan and/or magnetic resonance imaging. The following clinical data were prospectively collected: demographics, cancer treatment history, tumour stage, lymph node invasion, tumour differentiation, initial treatment, and survival. The predisposing disease or genetic syndrome was assessed by investigator declaration. The tumour blocks of either tumour biopsy from primary or metastasis or tumour surgical resection were collected.

\section{Immunohistochemistry}

Tissue microarrays (TMA) were constructed from 0.6-mm diameter tissue cores obtained from formalin fixed paraffin embedded tumor specimens. Hematoxylin and Eosin staining was performed on each TMA slide to confirm the presence of tumor tissue. The expression of MLH1, MSH2, MSH6, and PMS2 was assessed as previously described (9). Briefly, $4 \mu \mathrm{m}$ 
sections were cut onto silane-treated Super Frost slides (CML, Nemours, France) and left to dry at $37^{\circ} \mathrm{C}$ overnight. The slides were deparaffinised in xylene and rehydrated in pure ethanol. Endogenous peroxidase was blocked using 3\% hydrogen peroxide in methanol for 30 min. Before immunostaining, antigen retrieval was performed by immersing sections in citrate buffer (pH 6.0). Sections were then incubated for 15 minutes at room temperature with antibodies to MLH1 (dilution 1/70, clone G168-728, Pharmingen, San Diego, CA), MSH2 (dilution 1/100, clone FE11, Calbiochem, Oncogene Research Products, Cambridge, MA), MSH6 (dilution 1/100, clone 44, Becton Dickinson, Lexington, NC), PMS2 (clone A16-4, 1:150 dilution, BD PharMingen, Le Pont de Claix, France). The Bond Polymer Refine Detection kit (Leica) was used as the detection system. Immunostaining of MLH1, MSH2, MSH6 and PMS2 in tumour cells was evaluated as positive or negative as assessed in TMA. Tumours were considered negative when there was a complete absence of nuclear staining of neoplastic cells in the presence of an internal positive control assessed in a whole slide. All the tumour with a negative staining of one of the MMR protein were considered as dMMR.

\section{Molecular analysis}

The same paraffin blocks were used for DNA extractions and for IHC analyses. DNA was extracted from formalin-fixed, paraffin-embedded neoplastic tissue that had been macrodissected with reference to the Hematoxylin and Eosin stained section.

Next generation sequencing (NGS) investigates the presence of 739 hotspot somatic mutations in 46 genes involved in carcinogenesis using cancer hotspot panel from Thermofisher (Table S1). DNA extraction, NGS sequencing and mutation calling were performed as described previously (10). 


\section{Statistical analysis}

Descriptive analysis of the initial tumour stage (reference) and variables measured at baseline was performed. Categorical variables were summarised as frequencies and percentages and continuous variables as medians and ranges. The comparison of gene alteration frequencies according the sub-group of patients was assessed with the $X^{2}$ test or Fisher's exact test, as appropriate, for categorical variables.

Patients with metastatic disease were defined as those who had metastasis at the time of the inclusion and those who developed additional metastatic recurrence tumours during follow-up. Therefore, some patients in this trial were analysed twice: first, as cases with localized tumours, and second, as cases with metastases.

Overall survival (OS) was defined as the time from diagnosis of a primary tumour (localized tumour) or of metastasis (synchronous or metachronous) until death due to any cause. Patients who were still alive at the last follow-up were censored. Patients with synchronous resected metastasis were excluded from the analysis of metastatic patient subgroup in order to assess OS of patients with unresectable metastases.

The survival curves for OS were estimated by the Kaplan-Meier and were compared using the log-rank test. The follow-up time was assessed by the reverse Kaplan-Meier method. The medians and $95 \%$ confidence intervals (95\% Cls) were calculated and 3-year rates with $95 \% \mathrm{Cl}$ were also provided.

The hazard ratios (HRs) and their 95\% Cls were estimated with the Cox proportional hazard model. Univariate analysis was performed to determine baseline characteristics associated with OS for patients with mutational status available. All variables with $p$ values of $<0.1$ were 
included in multivariate analysis. The correlations between variables were assessed and proportional hazard assumptions were examined graphically by log-minus-log plots of survival. All statistical analyses were conducted with a two-sided alpha significance level of $5 \%$ using SAS 9.3 software (SAS institute Inc., Cary, NC, USA). As the analyses were exploratory, $p$ values were not adjusted for multiple testing.

\section{RESULTS}

\section{Patient and tumour characteristics}

Among the 347 patients included in the analysis of clinical NADEGE dataset, 196 tumour blocks were collected for immunohistochemistry and molecular analysis. The quantity or quality of extracted DNA could not allow molecular analysis in 71 tumours. Finally, the mutation status was obtained for 125 patients (Figure 1). Patient characteristics are presented in table 1. The clinical and tumour characteristics were comparable in the patients from the whole NADEGE (13) and the BIONADEGE cohorts except for metastatic stage at diagnosis underrepresented in the BIONADEGE cohort (36\% in NADEGE vs $18 \%$ in BIONADEGE, $\mathrm{p}<0.0001)$.

The gene mutation frequency according to tumour stage and primary are presented in table 2 . The detail of raw NGS data are presented in the table S1. Overall, at least one genomic alteration was observed in $90.4 \%$ of tumours. There is no difference into the frequency of at least one genomic alteration according to the tumour stage: $89.2 \%$ and $95.4 \%$ for localized or metastatic tumour at diagnosis, respectively. There was no difference into the frequency of at least one genomic alteration according to primary tumour site: $92.0 \%, 82.1 \%$ and $95.4 \%$ for 
duodenum, jejunum or ileum, respectively. Overall, the number of mutations observed per tumour was 0 in 9.6\%, 1 in 32.0\%, 2 in $26.4 \%$ and $>3$ in $32.0 \%$ of the patients. The proportion of tumours with $>3$ mutations were also similar according to stage: $30.4 \%$ and $40.9 \%$ for localized and metastatic tumours at diagnosis, respectively and according to primary: $33.3 \%$, $21.4 \%$ and $40.9 \%$ for duodenum, jejunum or ileum, respectively. The most frequent genomic alteration observed were: KRAS (44.0\%), TP53 (38.4\%), PIK3CA (20.0\%), APC (18.4\%), SMAD4 (14.4\%) and ERBB2 (7.2\%). A KRAS mutation was more frequent in metastatic tumours at diagnosis than in localized tumours $(72.7 \%$ vs $38.2 \%, p=0.003)$. A BRAF mutation was observed in $5(4 \%)$ cases and among them there is only one V600E mutation. There was no significant difference of mutation rate according to primary location for the most frequently altered genes.

The comparison of gene mutation frequency between patients with Lynch syndrome and those with no predisposing disease revealed different profiles (Table 3). There is a trend for less frequent KRAS mutations in Lynch syndrome and more frequent TP53 and PIK3CA mutations in Crohn's disease compare to no predisposing disease. No APC mutation was observed in any Crohn's disease. There is a trend of more frequent ERBB2 mutations in Lynch syndrome compare to no predisposing disease. Moreover, no ERBB2 mutation was observed in Crohn's disease. Several rare mutations are more frequent in tumour with Lynch syndrome than in no predisposing syndrome such as ATM, FGFR3 and FGFR1 gene mutations. IDH1 mutations are more frequent in tumours with Crohn's disease than in no predisposing disease.

\section{Results according to MMR status}

MMR status was determined with immunohistochemical (IHC) analysis of MMR proteins in 180 patients. A deficient MMR (dMMR) tumour was observed in $50(28 \%)$ patients. A negative 
staining was observed for both MLH1 and PMS2 in 21 (42\%), MSH2 and MSH6 in 18 (36\%), PMS2 with MLH1 inconclusive test in 4 (8\%), MSH6 with inconclusive MSH2 in 2 (4\%), PMS2 alone in 2 (4\%), MSH6 alone in 2 (4\%) and MSH2 with inconclusive MSH6 in one (2\%).

The comparisons of patient and tumour characteristics according to MMR status are given in table 4. The dMMR tumours were associated with a younger age, a less metastatic stage at diagnosis, less KRAS mutations but more SMARCB1 mutations. There is also a trend for less TP53 mutations and more ERBB2 mutations.

\section{Survival analysis}

The median follow-up was 56 months (95\% confidence interval $(\mathrm{Cl})$ [47-63]). The 3-years OS of the 196 patients with block available was $64.4 \%(95 \% \mathrm{Cl} 56.6 \%-71.1 \%)$ and $71.7 \%(95 \% \mathrm{Cl}$ $61.9 \%-79.4 \%)$ for the 125 patients with mutation status available.

\section{Survival analysis in the 125 patients with mutational status available}

Univariate analysis was performed in the sub-group of patients with mutation statuses available to assess the prognostic factors for OS including clinical parameters and the gene mutation with a frequency over $10 \%$ (Table 5). No genomic alteration was associated with OS (Table 5). In the multivariate analysis including stage, Lynch syndrome and tumour differentiation, only poor tumour differentiation remained associated with higher risk of death $(\mathrm{HR}=2.48 ; 95 \% \mathrm{Cl}[1.19-5.21] ; \mathrm{p}=0.0159)$. There is trend for a better prognosis associated with early stage $(p=0.0774)$ and Lynch syndrome $(p=0.0648)$.

The results of univariate analysis according to localized or metastatic tumour are given in table S2. In the sub-group of 102 patients with localized and resected tumour, no genomic alteration 
was associated with OS. There is a trend for a worst 3 years OS in patients with tumour KRAS mutation $(63.3 \%$ [95\% Cl 43.0 - 78.1] versus $82.0 \%$ [95\% $\mathrm{Cl} 69.1$ - 89.9], $\mathrm{p}=0.3551)$. In the subgroup of 31 patients with metastatic disease (unresectable synchronous metastasis and metachronous metastasis) the median OS was 22.6 months $(95 \% \mathrm{Cl} 12.7-59.7)$. No genomic alteration was associated with OS. Median OS was 32.3 months $(95 \% \mathrm{Cl} 12.5-59.7)$ and 21.0 months $(95 \% \mathrm{Cl} 8.1-36)$ in patients with mutated and wild type tumour KRAS, respectively $(p=0.5235)$. The median OS was $27.3(95 \% \mathrm{Cl} 9.1-59.7)$ and $16.2(95 \% \mathrm{Cl} 3.9-$ not assessable) in patients with mutated and wild type tumour TP53, respectively $(p=0.9123)$.

\section{Survival analysis in the 180 patients with MMR status available}

The 3-years OS rate was $79.9 \%(95 \% \mathrm{Cl} 64.7-89.1)$ for patients with dMMR tumours and 58.5 months $(95 \% \mathrm{Cl} 48.5-67.1)$ for patients with pMMR tumours. There is a trend for better survival in patients with dMMR tumours (HR=0.59; 95\% $\mathrm{Cl}$ [0.32-1.06], $\mathrm{p}=0.0765)$ (Figure S1). In the subgroup of patients with localized tumours the 3-years OS were $82.9 \%(95 \% \mathrm{Cl} 67.2-$ 91.5) and $72.5 \%(95 \% \mathrm{Cl} 60.2-81.6)$ for patients with dMMR and pMMR respectively (logrank $\mathrm{p}=0.3957 ; \mathrm{HR}=0.74$ [0.36-1.50], $\mathrm{p}=0.3976)$. Due to the small number of patients with a dMMR metastatic tumour $(n=2)$ the comparison of median OS according to MMR status was not reported.

\section{DISCUSSION}

Our study on a large number of patients with SBA revealed different tumour mutation profiles according to predisposing diseases (Crohn's disease or Lynch syndrome compared to tumour without predisposing disease) or an MMR status. 
Our results are concordant with the genomic alteration profile reported in three previous studies that reported a mutation rate for KRAS from $43.4 \%$ to $53.6 \%, T P 53$ from $41 \%$ to $58.4 \%$, PIK3CA from $9 \%$ to $18.4 \%$, APC from $13.2 \%$ to $26.8 \%$, SMAD4 from $9.6 \%$ to $17.4 \%$ and ERBB2 from $8.4 \%$ to $14 \%(7,8,10)$. Moreover, we found that KRAS mutations as pMMR status were associated with metastasis. This is the first report showing that a genomic alteration is associated with advanced stage in SBA to our best knowledge.

We found no significant association with one of the mutations observed in more than $5 \%$ of the tumour and primary tumour site. Two previous studies have reported an association with ERBB2 mutation and duodenal location $(7,10)$. In our study as in the Härinnen et al study (8) the ERBB2 mutation rate was higher in tumour of the proximal small bowel without reaching significance. Some rare mutations seem to have a different distribution according to the small bowel segment. IDH1 mutations were only reported in the ileum tumour which may be explained by the association with Crohn's disease that was mainly associated with ileum tumours in the NADEGE cohort (13). FBXW7 mutation was predominantly observed in the jejunum tumour. This result is concordant with the Schrock et al results that have reported a trend of more FBXW7 mutation in non-duodenal SBA (7).

The genomic alteration profile was different according to predisposing diseases or the MMR status. Crohn's disease was associated with tumour genomic alterations of IDH1. Moreover, a trend for more frequent $K D R$ mutations but no $A P C$ mutation was observed in Crohn's disease compare to no predisposing disease. IDH1 mutations and also high mutation rate of TP53 were already reported associated with Crohn's disease in colorectal cancer (14). A recent publication reported an association of IDH1 and SMAD4 mutations with Crohn's disease in SBA (15). We did not find any association of SMAD4 mutation and Crohn's disease in our study. Tumour KDR gene alteration, coding for VEGFR2, has not been previously reported to 
be associated to Crohn's disease. The lack of APC mutation in SBA associated with inflammatory bowel disease was already reported by Schrock et al (7). A lower frequency of $A P C$ mutation in colorectal cancer associated with inflammatory bowel disease as compared to sporadic colorectal cancer was also reported (14). No ERBB2 mutation was observed in tumour associated with Crohn's disease in our study as it was previously observed in the Schrock study (7). Altogether ours and previous results support the hypothesis that the SBA associated with Crohn's disease has a different carcinogenesis from sporadic cancer as it is observed in colorectal cancer (16).

In SBA associated with Lynch syndrome, there is a trend of less KRAS mutations and more ERBB2 mutations compared to tumours without predisposing diseases. Other rare mutations such as ATM, FGFR3 and FGFR1 are associated with Lynch syndrome in our study. The risk of developing a cancer for patient with Lynch syndrome if they had an ATM mutant allele is a matter of debate (17). We could not determine in our study if the ATM mutation was inherited or acquired. FGFR3 R248C hotspot mutation has already been associated to the Lynch syndrome in upper tract urothelial carcinoma (18) but not with SBA until our report.

We found some specificity in the subgroup of dMMR tumours compared to pMMR tumours. Patients with dMMR tumours are younger than patients with pMMR tumours. This is the inverse result that it is observed in colorectal cancer (19). That may be explained by the fact that in our study the proportion of Lynch syndrome among dMMR tumour reach 34\%. Nevertheless, as it is observed in colorectal cancer, the dMMR tumours are rarely metastatic at diagnosis. In our study, KRAS mutations are less frequent in dMMR tumours compared to pMMR tumours. This has not been previously reported in SBA and deserves a confirmatory study. There is also a trend for less TP53 alterations but more ERBB2 alterations in dMMR tumours than in pMMR tumours. The association of ERBB2 mutations and dMMR has previously been reported (10). 
We report a higher frequency of SMARCB1 mutations in dMMR tumours, SMARCB1 has already been described in dMMR colorectal tumours (20).

We did not find any association between genomic alteration and prognosis. One previous study reports a poor prognosis associated with a genomic alteration of the ERBB signalling cascade (11) but ERBB2 mutations solely had no prognostic value. The dMMR phenotype was already reported as good prognostic factor for disease free-survival in one study (8). In our study as in a previous one (9) there is a trend for better prognosis in patients with a dMMR tumour. The prognostic effect of dMMR phenotypes seems restricted to patients with localized and resected tumours. In patients with metastatic tumours the MMR status seems to have no effect. It must be pointed out that no patient with a dMMR tumour received immunotherapy. TP53 mutations were reported associated with poor survival in a previous study (12) but had no significant prognostic value in our study either in localized tumour or metastatic tumour like in another previous study (9). KRAS mutations were reported as a poor prognostic predictor in the subgroup of patients with a pT1-T3 tumour (21) but also associated with a better survival in patients with metastatic tumour (9). In our study there was no significant effect of KRAS mutation but a trend of a worst prognosis in localized tumours and a better prognosis in metastatic tumours. It has been previously reported that KRAS mutations were associated with a poor OS in colorectal stage III pMMR tumours (22). The prognostic value of KRAS mutations deserves further evaluation in SBA. A BRAF mutation was only observed in $4 \%$ of the tumours in our study. In previous studies the frequency of BRAF mutations range from $1 \%$ to $11 \%$ $(7,8,10,21)$. As in the previous studies the majority of $B R A F$ mutations reported in our study were not the $\mathrm{V} 600 \mathrm{E}$ mutation. No prognostic value of $B R A F$ mutations was reported in SBA. It must be pointed out that in metastatic colorectal cancer non-V600E BRAF mutations are not associated to a poor prognosis in contrast to the V600E BRAF mutations (23). 
Several genomic alterations reported in our study may be targeted. It has recently been reported that a treatment with immune checkpoint inhibitor gives a prolonged survival in patients with metastatic dMMR SBA (24). Preclinical data suggest that ERBB2 inhibitors reduce tumour growth of ERBB2 mutated tumours (11). Thus, ERBB2 inhibition deserve clinical evaluation in patients with ERBB2 mutated SBA. Other gene alterations of PTEN, PI3KCA or PTEN may be considered for targeted treatment (25). Some rare mutations deserve also further evaluation. Signal of efficacy have been reported with PARP inhibitors in patient with ATM deficiency (26). IDH1 inhibitions have shown efficacy in cholangiocarcinoma (27). IDH1 mutations should be screened in patient with SBA associated with Crohn's disease and IDH1 inhibitors need evaluation in those patients.

Our study had some limitations: first, even if this study is one of the largest genomic profiling of SBA, the sample size does not allow an accurate evaluation of rare mutation impact. Secondly, the gene panel used is limited but contains the most frequently altered genes in SBA. Thirdly, the constitutional gene mutations were not assessed in case of Lynch syndrome in our study. Fourth, we did not performed MSI testing nevertheless a previous study has reported no discordance between MMR IHC and MSI testing (9). Finally, we assume that our results are exploratory and should be taken with caution for the rare mutations as we did not perform a Bonferroni correction in our analysis. Moreover, the clinical characteristics were comparable in the NADEGE (13) and BIONADEGE cohorts except for metastatic stage at diagnostic underrepresented in the BIONADEGE cohort due to missing tumour samples suitable for genomic analysis. Thus, our results in metastatic tumours are limited. Additional studies pooling several databases are needed to specify the association of genomic profile, clinical data and prognosis. 
In conclusion, our study shows that there are different genomic alteration profiles in SBA that depends on the existence, or lack thereof, of a predisposing disease. This advocates to analyse separately sporadic SBA and those related to predisposing disease in future studies. With caution due to sample size, genomic alteration had no prognostic impact except a trend for a favourable prognosis associated with dMMR phenotypes in localized tumour. Nevertheless, some genomic alterations may be targeted. A compilation of worldwide experiences for off label targeted therapy is urgently needed for this orphan disease.

Previous presentation: This work has been presented at the 2019 ASCO meeting

\section{Acknowledgments}

BIONADEGE was granted by INCa and sponsor by Assistance Publique Hôpitaux de Paris (Délégation à la Recherche Clinique). ARCAD-NADEGE cohort was granted by A.R.C.A.D. and sponsored by GERCOR.

The authors thank to all investigators: Pauline Afchain (Paris), Thomas Aparicio (Paris), JeanBaptiste Bachet (Paris), Nathalie Bonichon-Lamichhane (Bordeaux), Laurent Cany (Périgueux), François Caroli-Bosc (Angers), Christos Christidis (Paris), Philippe Collin (Reims), Romain Coriat (Paris), David Deutsch (Bobigny), Joëlle Egreteau (Lorient), Pierre-Luc Etienne (Saint Brieuc), Francine Fein (Besançon), Johan Gagnière (Clermont-Ferrand), Claire GarnierTixidre (Grenoble), Vincenzo Giardina (Bezier), Jean-Marc Gornet (Paris), Victoire Granger (Grenoble), Rosine Guimbaud (Toulouse), Kamran Imani (Tarbes), Sandrine Lavau-Denes (Limoges), Cédric Lecaille (Bordeaux), Thierry Lecomte (Tours), Jean-Louis Legoux (Orléans), Astrid Lièvre (Rennes), Catherine Ligeza-Poisson (Saint Nazaire), Christophe Locher (Meaux), Catherine Lombard-Bohas (Lyon), May Mabro (Suresnes), Sylvain Manfredi (Dijon), André Mathieu (Narbonne), Jérôme Meunier (Orléans), Drifa Moussata (Lyon), Suzanne Nguyen 
(Beauvais), Arnaud Patenotte (Semur en Auxois), Hervé Perrier (Marseille), Guillaume Piessen (Lille), Marc Pocard (Lariboisière), Fabienne Portales (Montpellier), Corinne Sarda (Castre), Eric Terrebone (Pessac), David Tougeron (Poitiers), Aziz Zaanan (Paris).

The authors also thank Sabine Helfen and Zahia ben Abdesselam from the Clinical Research Unit and Clinical Research Centre, Avicenne Hospital, Bobigny as study manager, Mourad Benallaoua from Gastroenterology department for operational assistance, Alexandra Patry for technical assistance for tumour micro-array and Elsa Benamouzig for English editing.

Authors' contributions:

Study design: TA, MS, JH, DV and PLP.

Data acquisition: TA, MA, PA, AL, DT, JG, ET, GP, JLL, CL, MP, JMG, AZ, SLD, TL, DD and PLP.

Statistical analysis: JH and DV.

Manuscript preparation: TA, MS, JH, DV and PLP.

Manuscript review: all authors

\section{Funding}

This work was supported by a grant from INCa (Programme Hospitalier de Recherche Translationelle Cancer, PRTK14 $\mathrm{N}^{\circ}$ 091) and a grant $\mathrm{n}^{\circ}$ NA 2009 from the A.R.CA.D. foundation.

\section{Conflict of interest statement}

The authors declare no conflict of interest for this publication. 
Data availability statement: The datasets generated and/or analysed during the current study are available from the corresponding author on reasonable request.

Ethics Statement: All patients had to give written informed consent before inclusion into the NADEGE cohort study. This study was performed in accordance with the Declaration of Helsinki and was authorised by the ethics committee "lle de France II" No. ID-RCB: 2008A01058-47 and had the clinical trial number: NCT02976090.

\section{References}

1. Aparicio T, Zaanan A, Svrcek M, Laurent-Puig P, Carrere N, Manfredi S, et al. Small bowel adenocarcinoma: epidemiology, risk factors, diagnosis and treatment. Dig Liver Dis. 2014;46(2):97-104.

2. Bouvier A-M, Robaszkiewicz M, Jooste V, Cariou M, Drouillard A, Bouvier V, et al. Trends in incidence of small bowel cancer according to histology: a population-based study. J Gastroenterol. 2020;55(2):181-8.

3. Pan SY, Morrison H. Epidemiology of cancer of the small intestine. World J Gastrointest Oncol. 2011;3(3):33-42.

4. Legué LM, Bernards N, Gerritse SL, van Oudheusden TR, de Hingh IHJT, Creemers G-JM, et al. Trends in incidence, treatment and survival of small bowel adenocarcinomas between 1999 and 2013: a population-based study in The Netherlands. Acta Oncol. 2016;55(9-10):1183-9.

5. Faivre J, Trama A, De Angelis R, Elferink M, Siesling S, Audisio R, et al. Incidence, prevalence and survival of patients with rare epithelial digestive cancers diagnosed in Europe in 1995-2002. Eur J Cancer. 2012;48(10):1417-24.

6. Haan JC, Buffart TE, Eijk PP, van de Wiel MA, van Wieringen WN, Howdle PD, et al. Small bowel adenocarcinoma copy number profiles are more closely related to colorectal than to gastric cancers. Ann Oncol. 2012;23(2):367-74. 
7. Schrock AB, Devoe CE, McWilliams R, Sun J, Aparicio T, Stephens PJ, et al. Genomic Profiling of Small-Bowel Adenocarcinoma. JAMA Oncol. 2017;3(11):1546-53.

8. Hänninen UA, Katainen R, Tanskanen T, Plaketti R-M, Laine R, Hamberg J, et al. Exome-wide somatic mutation characterization of small bowel adenocarcinoma. PLoS Genet. 2018;14(3):e1007200.

9. Aparicio T, Svrcek M, Zaanan A, Beohou E, Laforest A, Afchain P, et al. Small bowel adenocarcinoma phenotyping, a clinicobiological prognostic study. Br J Cancer. 2013;109(12):3057-66.

10. Laforest A, Aparicio T, Zaanan A, Silva FP, Didelot A, Desbeaux A, et al. ERBB2 gene as a potential therapeutic target in small bowel adenocarcinoma. Eur J Cancer. 2014;50(10):1740-6.

11. Adam L, San Lucas FA, Fowler R, Yu Y, Wu W, Liu Y, et al. DNA Sequencing of Small Bowel Adenocarcinomas Identifies Targetable Recurrent Mutations in the ERBB2 Signaling Pathway. Clin Cancer Res. 2019;25(2):641-51.

12. Alvi MA, McArt DG, Kelly P, Fuchs $M-A$, Alderdice $M$, McCabe $C M$, et al. Comprehensive molecular pathology analysis of small bowel adenocarcinoma reveals novel targets with potential for clinical utility. Oncotarget. 2015;6(25):20863-74.

13. Aparicio T, Henriques J, Manfredi S, Tougeron D, Bouché O, Pezet $D$, et al. Small bowel adenocarcinoma: Results from a nationwide prospective ARCAD-NADEGE cohort study of 347 patients. Int J Cancer. 2020;147(4):967-977.

14. Yaeger R, Shah MA, Miller VA, Kelsen JR, Wang K, Heins ZJ, et al. Genomic Alterations Observed in Colitis-Associated Cancers Are Distinct From Those Found in Sporadic Colorectal Cancers and Vary by Type of Inflammatory Bowel Disease. Gastroenterology. 2016;151(2):278-287.e6.

15. Liao X, Li G, McBride R, Houldsworth J, Harpaz N, Polydorides AD. Clinicopathological and Molecular Characterisation of Crohn's Disease-associated Small Bowel Adenocarcinomas. J Crohns Colitis. 2020;14(3):287-94.

16. Ullman TA, Itzkowitz SH. Intestinal inflammation and cancer. Gastroenterology. 2011;140(6):1807-16.

17. Jones JS, Gu X, Lynch PM, Rodriguez-Bigas M, Amos Cl, Frazier ML. ATM polymorphism and hereditary nonpolyposis colorectal cancer (HNPCC) age of onset (United States). Cancer Causes Control. 2005;16(6):749-53.

18. Donahu TF, Bagrodia A, Audenet F, Donoghue MTA, Cha EK, Sfakianos JP, et al. Genomic Characterization of Upper-Tract Urothelial Carcinoma in Patients With Lynch Syndrome. JCO Precis Oncol. 2018;2018:PO.17.00143. 
19. Aparicio T, Schischmanoff O, Poupardin C, Mary F, Soufir N, Barrat C, et al. High prevalence of deficient mismatch repair phenotype and the V600E BRAF mutation in elderly patients with colorectal cancer. J Geriatr Oncol. 2014;5(4):384-8.

20. Kondelin J, Salokas K, Saarinen L, Ovaska K, Rauanheimo H, Plaketti R-M, et al. Comprehensive evaluation of coding region point mutations in microsatellite-unstable colorectal cancer. EMBO Mol Med. 2018;10(9).

21. Jun S-Y, Kim M, Jin Gu M, Kyung Bae $Y$, Chang H-K, Sun Jung E, et al. Clinicopathologic and prognostic associations of KRAS and BRAF mutations in small intestinal adenocarcinoma. Mod Pathol. 2016;29(4):402-15.

22. Taieb J, Le Malicot K, Shi Q, Penault-Llorca F, Bouché O, Tabernero J, et al. Prognostic Value of BRAF and KRAS Mutations in MSI and MSS Stage III Colon Cancer. J Natl Cancer Inst. 2017;109(5).

23. Jones JC, Renfro LA, Al-Shamsi HO, Schrock AB, Rankin A, Zhang BY, et al. Non-V600 BRAF Mutations Define a Clinically Distinct Molecular Subtype of Metastatic Colorectal Cancer. J Clin Oncol. 2017;35(23):2624-30.

24. Marabelle A, Le DT, Ascierto PA, Di Giacomo AM, De Jesus-Acosta A, Delord J-P, et al. Efficacy of Pembrolizumab in Patients With Noncolorectal High Microsatellite Instability/Mismatch RepairDeficient Cancer: Results From the Phase II KEYNOTE-158 Study. J Clin Oncol. 2020;38(1):1-10.

25. Mateo J, Chakravarty D, Dienstmann R, Jezdic S, Gonzalez-Perez A, Lopez-Bigas N, et al. A framework to rank genomic alterations as targets for cancer precision medicine: the ESMO Scale for Clinical Actionability of molecular Targets (ESCAT). Ann Oncol. 2018;29(9):1895-902.

26. Jette NR, Kumar M, Radhamani S, Arthur G, Goutam S, Yip S, et al. ATM-Deficient Cancers Provide New Opportunities for Precision Oncology. Cancers. 2020;12(3).

27. Lowery MA, Burris HA, Janku F, Shroff RT, Cleary JM, Azad NS, et al. Safety and activity of ivosidenib in patients with IDH1-mutant advanced cholangiocarcinoma: a phase 1 study. Lancet Gastroenterol Hepatol. 2019;4(9):711-20.

\section{Figure legends}

Figure 1: Flow chart 


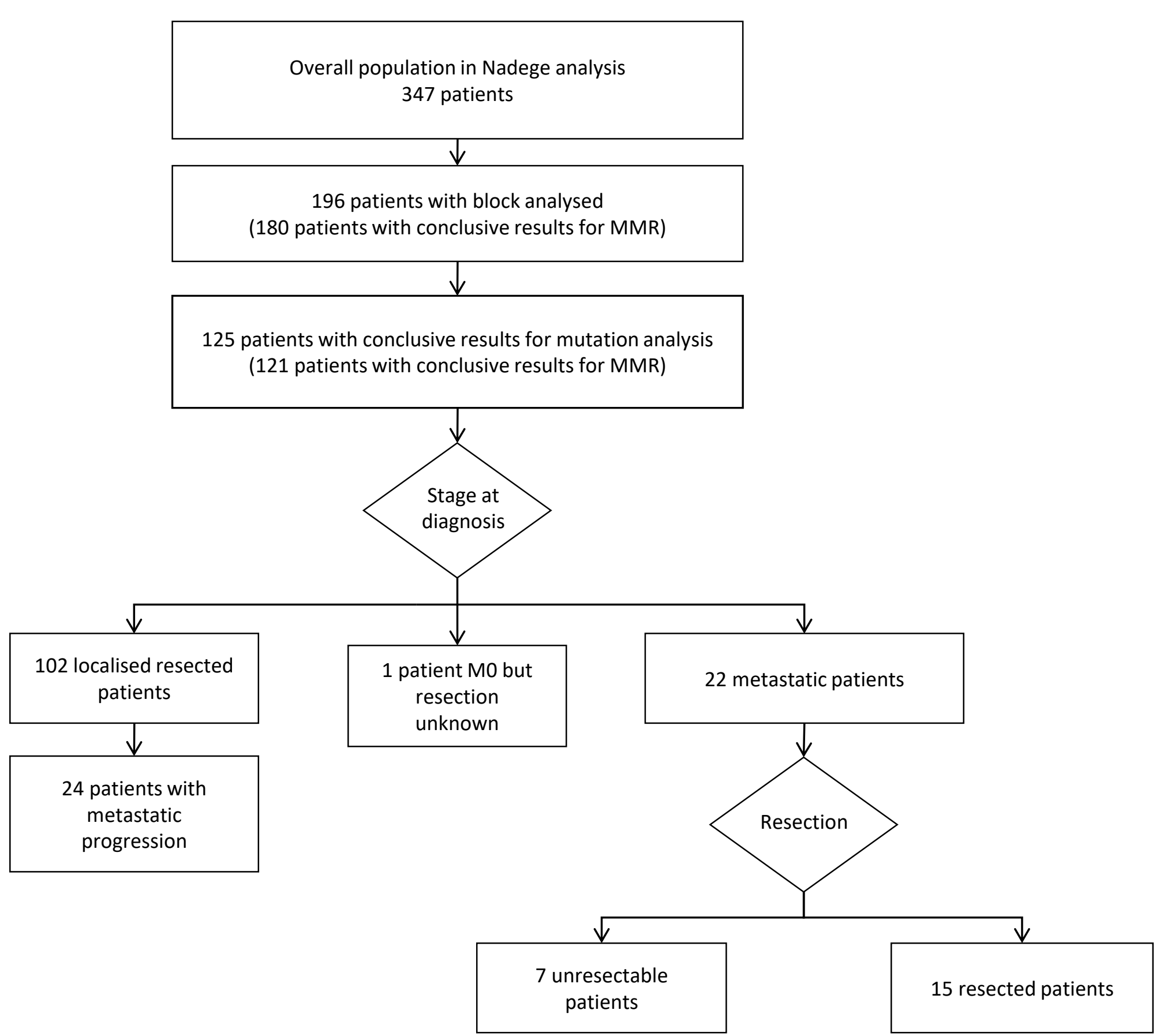


Table 1: Patient's characteristics

\begin{tabular}{|c|c|c|c|c|}
\hline Characteristics & & $\begin{array}{l}\text { Whole NADEGE } \\
\text { population } \\
\mathrm{N}=347(\%)\end{array}$ & $\begin{array}{l}\text { Tumour block } \\
\text { available } \\
\mathrm{N}=196 \text { (\%) }\end{array}$ & $\begin{array}{l}\text { Molecular } \\
\text { genotyping } \\
\mathrm{N}=125 \text { (\%) }\end{array}$ \\
\hline Sex & $\begin{array}{l}\text { Male } \\
\text { Female }\end{array}$ & $\begin{array}{l}204(59.0) \\
142(41.1)\end{array}$ & $\begin{array}{l}105(53.6) \\
91(46.4)\end{array}$ & $\begin{array}{l}66(52.8) \\
59(47.2)\end{array}$ \\
\hline Age & Median (range) & $62(22-90)$ & $63(24-90)$ & $61.7(24-88)$ \\
\hline $\begin{array}{l}\text { Predisposing disease } \\
n=346\end{array}$ & $\begin{array}{l}\text { no } \\
\text { Yes } \\
\text { Lynch syndrome } \\
\text { Crohn's disease } \\
\text { Familial polyposis syndrome } \\
\text { Coeliac disease } \\
\text { Peutz-Jeghers syndrome }\end{array}$ & $\begin{array}{l}278(80.3) \\
68(19.6) \\
24(6.9) \\
30(8.5) \\
6(1.7) \\
6(1.7) \\
2(0.6)\end{array}$ & $\begin{array}{l}159(81.1) \\
37(18.9) \\
17(8.7) \\
12(6.1) \\
5(2.6) \\
2(1.0) \\
1(0.5)\end{array}$ & $\begin{array}{l}100(80) \\
25(20) \\
14(11.2) \\
7(5.6) \\
2(1.6) \\
1(0.8) \\
1(0.8)\end{array}$ \\
\hline $\begin{array}{l}\text { Primary tumour site } \\
\mathrm{N}=343\end{array}$ & $\begin{array}{l}\text { Duodenum } \\
\text { Jejunum } \\
\text { Ileum }\end{array}$ & $\begin{array}{c}208(60.6) \\
71(20.7) \\
64(18.7)\end{array}$ & $\begin{array}{r}128(65.6) \\
35(18.0) \\
32(16.4)\end{array}$ & $\begin{array}{l}75(60) \\
28(22.4) \\
22(17.6)\end{array}$ \\
\hline
\end{tabular}




\begin{tabular}{|l|l|l|l|l|}
\hline Stage at diagnosis & $\mathrm{N}=343$ & $\mathrm{~N}=194$ & $\mathrm{~N}=124$ \\
Localized and resected & $202(58.9)$ & $135(69.6)$ & $102(82.3)$ \\
& Stage 0 (T in situ) & $5(2.5)$ & $4(3.0)$ & $1(1.0)$ \\
& Stage I & $17(8.4)$ & $13(9.6)$ & $11(10.8)$ \\
& Stage II & $67(33.2)$ & $42(31.1)$ & $36(35.3)$ \\
& Stage III & $99(49.0)$ & $68(50.4)$ & $50(49.0)$ \\
Locally advanced and not resected & $14(6.9)$ & $8(5.9)$ & $4(3.9)$ \\
Metastatic & Unknown & $19(5.5)$ & $8(4.1)$ & $0(0.0)$ \\
\hline Histological grade & Well/moderately differentiated & $254(73.2)$ & $156(79.6)$ & $102(81.6)$ \\
\hline & Poorly differentiated & $67(19.3)$ & $36(18.4)$ & $23(18.4)$ \\
\hline & Unknown & $26(7.5)$ & $4(2.0)$ & $0(0.0)$ \\
\hline
\end{tabular}


Table 2: Gene mutation according to tumour stage and primary

\begin{tabular}{|c|c|c|c|c|c|c|c|c|}
\hline Gene mutation & $\begin{array}{c}\begin{array}{c}\text { Overall } \\
\text { population } \\
(n=125)\end{array} \\
\end{array}$ & $\begin{array}{c}\text { Localized } \\
\text { and } \\
\text { resected } \\
(n=102)\end{array}$ & $\begin{array}{c}\text { Metastatic } \\
\text { at } \\
\text { diagnosis } \\
(n=22)\end{array}$ & & $\begin{array}{c}\text { Duodenum } \\
(\mathrm{n}=75)\end{array}$ & $\begin{array}{c}\text { Jejunum } \\
(\mathrm{n}=\mathbf{2 8})\end{array}$ & $\begin{array}{l}\text { Ileum } \\
(n=22)\end{array}$ & \\
\hline & $\%$ & $\%$ & $\%$ & $P$ value & $\%$ & $\%$ & $\%$ & $P$ value \\
\hline KRAS & 44.0 & 38.2 & 72.7 & 0.0031 & 48.0 & 32.1 & 45.4 & 0.3493 \\
\hline TP53 & 38.4 & 37.3 & 45.5 & 0.4739 & 33.3 & 43.9 & 50.0 & 0.3165 \\
\hline PIK3CA & 20.0 & 19.6 & 22.7 & 0.7718 & 18.7 & 14.3 & 31.8 & 0.2759 \\
\hline$A P C$ & 18.4 & 14.7 & 31.8 & 0.0690 & 18.7 & 17.9 & 18.2 & 0.9951 \\
\hline SMAD4 & 14.4 & 11.8 & 27.3 & 0.0899 & 16.0 & 7.1 & 18.2 & 0.4909 \\
\hline ERBB2 & 7.2 & 7.8 & 0.0 & 0.3484 & 8.0 & 7.1 & 4.5 & 1 \\
\hline ATM & 5.6 & 6.8 & 0.0 & 0.3509 & 6.7 & 3.6 & 4.5 & 1 \\
\hline PTEN & 5.6 & 4.9 & 9.1 & 0.6065 & 6.7 & 0.0 & 9.1 & 0.2983 \\
\hline NRAS & 4.8 & 4.9 & 4.5 & 1 & 1.3 & 14 & 4.5 & 0.0202 \\
\hline BRAF & 4.0 & 4.9 & 0.0 & 0.5848 & 4.0 & 3.6 & 4.5 & 1 \\
\hline CTNNB1 & 4.0 & 3.9 & 4.5 & 1 & 2.7 & 11.0 & 0.0 & 0.1397 \\
\hline STK11 & 4.0 & 3.9 & 4.5 & 1 & 4.0 & 0.0 & 9.1 & 0.2062 \\
\hline CDKN2A & 3.2 & 3.9 & 0.0 & 1 & 2.7 & 7.1 & 0.0 & 0.3498 \\
\hline$F B X W 7$ & 3.2 & 3.9 & 0.0 & 1 & 1.3 & 11.0 & 0.0 & 0.0610 \\
\hline$A B L 1$ & 2.4 & 1.9 & 4.5 & 0.4464 & 2.7 & 0.0 & 4.5 & 0.5430 \\
\hline FGFR3 & 2.4 & 2.9 & 0.0 & 1 & 4.0 & 0.0 & 0.0 & 0.7555 \\
\hline GNAS & 2.4 & 2.9 & 0.0 & 1 & 4.0 & 0.0 & 0.0 & 0.7555 \\
\hline IDH1 & 2.4 & 2.9 & 0.0 & 1 & 0.0 & 3.6 & 9.1 & 0.0355 \\
\hline SMARCB1 & 2.4 & 2.9 & 0.0 & 1 & 4.0 & 0.0 & 0.0 & 0.7555 \\
\hline
\end{tabular}




\begin{tabular}{|l|l|l|l|l|l|l|l|l|} 
EGFR & 1.6 & 0.9 & 4.5 & 0.3245 & 0.0 & 3.6 & 4.5 & 0.1581 \\
\hline ERBB4 & 1.6 & 0.9 & 4.5 & 0.3245 & 0.0 & 3.6 & 4.5 & 0.1581 \\
\hline FGFR1 & 1.6 & 1.9 & 0.0 & 1 & 2.7 & 0.0 & 0.0 & 1 \\
\hline MET & 1.6 & 0.9 & 4.5 & 0.3245 & 2.7 & 0.0 & 0.0 & 1 \\
\hline SMO & 1.6 & 1.9 & 0.0 & 1 & 1.3 & 0.0 & 4.5 & 0.3710 \\
\hline AKT1 & 0.8 & 0.9 & 0.0 & 1 & 0.0 & 3.6 & 0.0 & 0.4000 \\
\hline CDH1 & 0.8 & 0.9 & 0.0 & 1 & 0.0 & 3.6 & 0.0 & 0.4000 \\
\hline FGFR2 & 0.8 & 0.9 & 0.0 & 1 & 1.3 & 0.0 & 0.0 & 1 \\
\hline FLT3 & 0.8 & 0.9 & 0.0 & 1 & 0.0 & 3.6 & 0.0 & 0.4000 \\
\hline IDH2 & 0.8 & 0.9 & 0.0 & 1 & 1.3 & 0.0 & 0.0 & 1 \\
\hline JAK3 & 0.8 & 0.9 & 0.0 & 1 & 1.3 & 0.0 & 0.0 & 1 \\
\hline KDR & 0.8 & 0.9 & 0.0 & 1 & 0.0 & 0.0 & 4.5 & 0.1760 \\
\hline PDGFRA & 0.8 & 0.9 & 0.0 & 1 & 1.3 & 0.0 & 0.0 & 1 \\
\hline PTPN11 & 0.8 & 0.9 & 0.0 & 1 & 1.3 & 0.0 & 0.0 & 1 \\
\hline SRC & 0.8 & 0.9 & 0.0 & 1 & 1.3 & 0.0 & 0.0 & 1 \\
\hline RB1 & 0.0 & 0.0 & 0.0 & - & 0.0 & 0.0 & 0.0 & 1 \\
\hline
\end{tabular}


Table 3: Gene mutation according to predisposing disease

\begin{tabular}{|c|c|c|c|c|c|}
\hline & $\begin{array}{c}\text { No predisposing } \\
\text { disease }\end{array}$ & $\begin{array}{c}\text { Lynch } \\
\text { Syndrome }\end{array}$ & $P$ value & $\begin{array}{l}\text { Crohn's } \\
\text { disease }\end{array}$ & $P$ value \\
\hline & $(n=100)$ & $(n=14)$ & $\begin{array}{c}\text { Lynch vs no predisposing } \\
\text { disease }\end{array}$ & $(n=7)$ & $\begin{array}{c}\text { Crohn vs no } \\
\text { predisposing } \\
\text { disease }\end{array}$ \\
\hline & $\%$ & $\%$ & & $\%$ & \\
\hline KRAS & 48.0 & 21.4 & 0.0611 & 42.9 & 1 \\
\hline TP53 & 39.0 & 21.4 & 0.2018 & 71.4 & 0.1211 \\
\hline PIKЗCA & 18.0 & 28.6 & 0.4671 & 42.9 & 0.1348 \\
\hline$A P C$ & 20.0 & 14.3 & 1 & 0.0 & 0.3435 \\
\hline SMAD4 & 16.0 & 7.1 & 0.6899 & 14.3 & 1 \\
\hline ERBB2 & 7.0 & 14.3 & 0.3046 & 0.0 & 1 \\
\hline ATM & 4.0 & 21.4 & 0.0389 & 0.0 & 1 \\
\hline PTEN & 5.0 & 7.1 & 0.553 & 0.0 & 1 \\
\hline$N R A S$ & 6.0 & 0.0 & 1 & 0.0 & 1 \\
\hline$B R A F$ & 5.0 & 0.0 & 1 & 0.0 & 1 \\
\hline CTNNB1 & 5.0 & 0.0 & 1 & 0.0 & 1 \\
\hline STK11 & 4.0 & 0.0 & 1 & 14.3 & 0.2918 \\
\hline CDKN2A & 3.0 & 7.1 & 0.4124 & 0.0 & 1 \\
\hline$F B X W 7$ & 2.0 & 14.3 & 0.0731 & 0.0 & 1 \\
\hline$A B L 1$ & 2.0 & 0 & 1 & 14.3 & 0.1853 \\
\hline FGFR3 & 1.0 & 14.3 & 0.0394 & 0.0 & 1 \\
\hline GNAS & 2.0 & 7.1 & 0.3276 & 0.0 & 1 \\
\hline IDH1 & 1.0 & 0.0 & 1 & 28.6 & 0.0108 \\
\hline
\end{tabular}




\begin{tabular}{|l|c|c|c|c|c|}
\hline SMARCB1 & 2.0 & 7.1 & 0.3276 & 0.0 & 1 \\
\hline EGFR & 1.0 & 7.1 & 0.2315 & 0.0 & 1 \\
\hline ERBB4 & 1.0 & 0.0 & 1 & 14.3 & 0.1271 \\
\hline FGFR1 & 0.0 & 14.3 & 0.0141 & 0.0 & - \\
\hline MET & 1.0 & 7.1 & 0.2315 & 0.0 & 1 \\
\hline SMO & 2.0 & 0.0 & 1 & 0.0 & 1 \\
\hline AKT1 & 0.0 & 7.1 & 0.1228 & 0.0 & - \\
\hline CDH1 & 0.0 & 7.1 & 0.1228 & 0.0 & - \\
\hline FGFR2 & 0.0 & 7.1 & 0.1228 & 0.0 & - \\
\hline FLT3 & 1.0 & 0.0 & 1 & 0.0 & 1 \\
\hline IDH2 & 0.0 & 7.1 & 0.1228 & 0.0 & - \\
\hline JAK3 & 1.0 & 0.0 & 1 & 0.0 & 1 \\
\hline KDR & 0.0 & 0.0 & - & 14.3 & 0.0654 \\
\hline PDGFRA & 1.0 & 0.0 & 1 & 0.0 & 1 \\
\hline PTPN11 & 0.0 & 7.1 & 0.1228 & 0.0 & - \\
\hline SRC & 1.0 & 0.0 & 1 & 0.0 & 1 \\
\hline RB1 & 0.0 & 0.0 & - & 0.0 & - \\
\hline
\end{tabular}


Table 4: Patients and tumour characteristics according to MMR status

\begin{tabular}{|c|c|c|c|}
\hline Characteristics & $\begin{array}{c}\text { pMMR } \\
\text { tumours } \\
n=130 \\
(72.2 \%) \\
\end{array}$ & $\begin{array}{l}\text { dMMR tumours } \\
n=50(27.8 \%)\end{array}$ & $P$ value \\
\hline Sex: Men & $67(51.5 \%)$ & $28(56.0 \%)$ & \\
\hline Women & $63(48.5 \%)$ & $22(44.0 \%)$ & 0.5912 \\
\hline Age (median) & 64 & 58 & 0.1760 \\
\hline Primary: Duodenum & $83(64.3 \%)$ & $33(66.0 \%)$ & \\
\hline Jejunum & $22(17.0 \%)$ & $11(22.0 \%)$ & \\
\hline Ileum & $24(18.6 \%)$ & $6(12.0 \%)$ & 0.4889 \\
\hline Stage at diagnosis & $n=129$ & $\mathrm{n}=49$ & \\
\hline Localized and resected: & $81(62.8 \%)$ & $47(95.9 \%)$ & \\
\hline Stage 0 (in situ) & $3(3.7 \%)$ & $0(0 \%)$ & \\
\hline Stage I & $7(8.6 \%)$ & $5(10.6 \%)$ & \\
\hline Stage II & $25(30.9 \%)$ & $17(36.2 \%)$ & \\
\hline Stage III & $40(49.4 \%)$ & $23(48.9 \%)$ & \\
\hline Unknown & $6(7.4 \%)$ & $2(4.3 \%)$ & \\
\hline $\begin{array}{l}\text { Locally advanced and not resected } \\
\text { Metastatic }\end{array}$ & $\begin{array}{c}7(5.4 \%) \\
41(31.8 \%) \\
\end{array}$ & $\begin{array}{c}0(0 \%) \\
2(4.1 \%) \\
\end{array}$ & $<0.0001$ \\
\hline Grade: Well/moderately differentiated & $106(83.5 \%)$ & $40(80.0 \%)$ & \\
\hline Poorly differentiated & $21(16.5 \%)$ & $10(20.0 \%)$ & 0.5851 \\
\hline Lynch syndrome & $0(0.0 \%)$ & $17(34.0 \%)$ & $<0.0001$ \\
\hline Crohn disease & $9(6.9 \%)$ & $2(4.0 \%)$ & 0.7300 \\
\hline
\end{tabular}




\begin{tabular}{|c|c|c|c|}
\hline $\begin{array}{l}\text { Sub group of patients with molecular } \\
\text { phenotyping }\end{array}$ & $n=81(66.9 \%)$ & $\mathrm{n}=40(33.1 \%)$ & $\mathbf{P}$ value \\
\hline KRAS & $44(54.3 \%)$ & $9(22,5 \%)$ & 0.0009 \\
\hline TP53 & 35 (43.2\%) & $11(27.5 \%)$ & 0.0940 \\
\hline PIK3CA & $17(21.0 \%)$ & $8(20.0 \%)$ & 0.8996 \\
\hline$A P C$ & $17(21.0 \%)$ & $5(12.5 \%)$ & 0.25481 \\
\hline SMAD4 & $14(17.3 \%)$ & $3(7.5 \%)$ & 0.1451 \\
\hline ERBB2 & $3(3.7 \%)$ & $6(15.0 \%)$ & 0.0580 \\
\hline ATM & $3(3.7 \%)$ & $4(10.0 \%)$ & 0.2175 \\
\hline PTEN & $3(3.7 \%)$ & $4(10.0 \%)$ & 0.2175 \\
\hline NRAS & $4(4.94 \%)$ & $1(2.5 \%)$ & 1 \\
\hline$B R A F$ & $3(3.7 \%)$ & $2(5.0 \%)$ & 1 \\
\hline CTNNB1 & $3(3.7 \%)$ & $1(2.5 \%)$ & 1 \\
\hline STK11 & $3(3.7 \%)$ & $2(5.0 \%)$ & 1 \\
\hline CDKN2A & $2(2.5 \%)$ & $2(5.0 \%)$ & 0.5983 \\
\hline FBXW7 & $2(2.5 \%)$ & $2(5.0 \%)$ & 0.5983 \\
\hline$A B L 1$ & $2(2.5 \%)$ & $1(2.5 \%)$ & 1 \\
\hline FGFR3 & 1 (1.2\%) & $2(5.0 \%)$ & 0.2537 \\
\hline GNAS & $1(1.2 \%)$ & $2(5.0 \%)$ & 0.2537 \\
\hline$I D H 1$ & $3(3.7 \%)$ & $0(0.0 \%)$ & 0.5500 \\
\hline SMARCB1 & $0(0 \%)$ & $3(7.5 \%)$ & 0.0343 \\
\hline EGFR & $1(1.2 \%)$ & $1(2.5 \%)$ & 1 \\
\hline ERBB4 & $1(1.2 \%)$ & $1(2.5 \%)$ & 1 \\
\hline FGFR1 & $1(1.2 \%)$ & $1(2,5 \%)$ & 1 \\
\hline$M E T$ & $0(0 \%)$ & $1(2.5 \%)$ & 0.3306 \\
\hline SMO & $1(1.2 \%)$ & $1(2.5 \%)$ & 1 \\
\hline AKT1 & $0(0 \%)$ & $1(2.5 \%)$ & 0.3306 \\
\hline $\mathrm{CDH1}$ & $0(0 \%)$ & $1(2.5 \%)$ & 0.3306 \\
\hline FGFR2 & $0(0 \%)$ & $1(2.5 \%)$ & 0.3306 \\
\hline FLT3 & $1(1.2 \%)$ & $0(0 \%)$ & 1 \\
\hline IDH2 & $0(0 \%)$ & $1(2.5 \%)$ & 0.3306 \\
\hline$J A K 3$ & $1(1.2 \%)$ & $0(0 \%)$ & 1 \\
\hline$K D R$ & $1(1.2 \%)$ & $0(0 \%)$ & 1 \\
\hline PDGFRA & $0(0 \%)$ & $1(2.5 \%)$ & 0.3306 \\
\hline
\end{tabular}




\begin{tabular}{|l|c|c|c|}
\hline PTPN11 & $0(0 \%)$ & $1(2.5 \%)$ & 0.3306 \\
\hline SRC & $1(1.2 \%)$ & $0(0 \%)$ & 1 \\
\hline RB1 & $0(0 \%)$ & $0(0 \%)$ & - \\
\hline
\end{tabular}

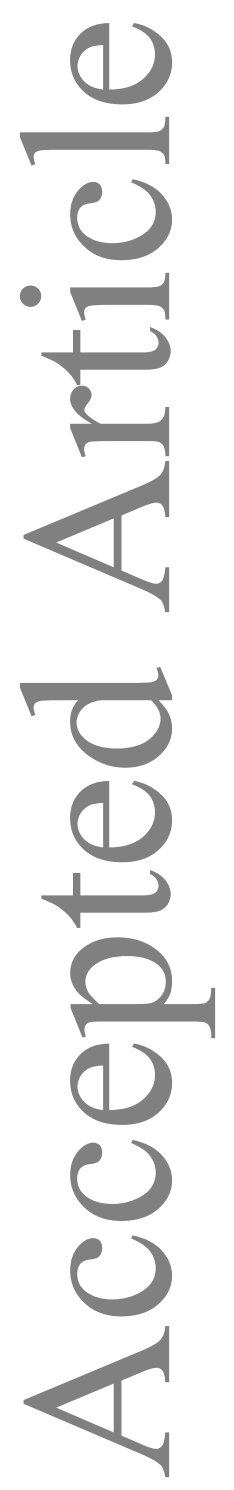


Table 5: Hazard ratio of death according to clinical and tumour characteristics in univariate analysis

\begin{tabular}{|c|c|c|c|c|c|}
\hline Characteristics & & n (events) & HR & $95 \% \mathrm{Cl}$ & P value \\
\hline \multirow[t]{2}{*}{ Gender } & male & $66(19)$ & 1 & & 0.5927 \\
\hline & female & $59(22)$ & 1.18 & $0.64-2.19$ & \\
\hline \multirow[t]{2}{*}{ Age } & $<70$ & $87(28)$ & 1 & & 0.1687 \\
\hline & $\geq 70$ & $38(13)$ & 1.6 & $0.82-3.15$ & \\
\hline \multirow[t]{3}{*}{ Primary } & Duodenum & $75(25)$ & 1 & & 0.2929 \\
\hline & Jejunum & $28(7)$ & 0.6 & $0.26-1.39$ & 0.2331 \\
\hline & Ileum & $22(9)$ & 1.31 & $0.61-2.82$ & 0.4864 \\
\hline \multirow[t]{2}{*}{ Differentiation } & $\begin{array}{l}\text { Well/moderately } \\
\text { differentiated }\end{array}$ & $102(30)$ & 1 & & 0.0549 \\
\hline & $\begin{array}{l}\text { Poorly } \\
\text { differentiated }\end{array}$ & $23(11)$ & 1.97 & $0.99-3.95$ & \\
\hline \multirow[t]{2}{*}{ Predisposing disease } & No & $100(36)$ & 1 & & 0.1026 \\
\hline & Yes & $25(5)$ & 0.46 & $0.18-1.17$ & \\
\hline \multirow[t]{4}{*}{ Stage at diagnostic } & 0 or I & $12(2)$ & 1 & & 0.0612 \\
\hline & II & $36(8)$ & 1.63 & $0.35-7.66$ & 0.5393 \\
\hline & III & $51(19)$ & 2.69 & $0.62-11.55$ & 0.1844 \\
\hline & IV & $22(11)$ & 4.75 & $1.04-21.61$ & 0.0438 \\
\hline \multirow[t]{2}{*}{$\mathrm{pN}$} & No & $52(10)$ & 1 & & 0.0206 \\
\hline & N1 & $64(26)$ & 2.37 & $1.14-4.92$ & \\
\hline \multirow[t]{3}{*}{ pT } & 1 or 2 & $16(2)$ & 1 & & 0.0065 \\
\hline & 3 & $61(14)$ & 2.33 & $0.53-10.27$ & 0.2630 \\
\hline & 4 & $41(20)$ & 5.73 & $1.33-24.6$ & 0.0190 \\
\hline \multirow[t]{2}{*}{$\mathrm{M}$} & MO & $103(30)$ & 1 & & 0.0214 \\
\hline & M1 & $22(11)$ & 2.28 & $1.13-4.6$ & \\
\hline \multirow[t]{2}{*}{ MMR } & pMMR & $81(27)$ & 1 & & 0.2634 \\
\hline & dMMR & $40(11)$ & 0.67 & $0.33-1.35$ & \\
\hline \multirow[t]{2}{*}{ Lynch syndrome } & No & $111(39)$ & 1 & & 0.0895 \\
\hline & Yes & $14(2)$ & 0.29 & $0.07-1.21$ & \\
\hline \multirow[t]{2}{*}{ KRAS } & wild-type & $70(23)$ & 1 & & 0.5760 \\
\hline & mutated & $55(18)$ & 1.19 & $0.64-2.22$ & \\
\hline \multirow[t]{2}{*}{ TP53 } & wild-type & $77(22)$ & 1 & & 0.4944 \\
\hline & mutated & $48(19)$ & 1.24 & $0.67-2.29$ & \\
\hline \multirow[t]{2}{*}{$A P C$} & wild-type & $102(36)$ & 1 & & 0.2220 \\
\hline & mutated & $23(5)$ & 0.56 & $0.22-1.42$ & \\
\hline \multirow[t]{2}{*}{ PIK3CA } & wild-type & $100(33)$ & 1 & & 0.4877 \\
\hline & mutated & $25(8)$ & 1.32 & $0.61-2.85$ & \\
\hline \multirow[t]{2}{*}{ SMAD4 } & wild-type & $107(35)$ & 1 & & 0.5653 \\
\hline & mutated & $18(6)$ & 1.29 & $0.54-3.08$ & \\
\hline
\end{tabular}

